\title{
AN AGGREGATE PRODUCTION PLANNING MODEL FOR PAINT INDUSTRY IN FUZZY ENVIRONMENT
}

\author{
M. N. Fors*, A. Eldomiaty**, M. A. Zaghloul** and S. A. Elsanabary** \\ * Production Engineering Dept., Faculty of Engineering, Alexandria University, Egypt \\ ** Production Engineering Dept., Faculty of Engineering, Sues Canal University, Egypt
}

\begin{abstract}
This work presents Aggregate Production planning (APP) in fuzzy environment for paint industry. In real-world APP problems, input data or parameters, such as demand, resources, costs are fuzzy / imprecise in nature because some information is incomplete or unobtainable. This study applying Possibilistic Linear Programming (PLP) to solve multi- product and multi- period APP problem with fuzzy / imprecise objective and cost coefficients by triangular possibility distributions under uncertainty. The APP model designed to minimize total production costs, while considering inventory level, labor levels, and machine capacity. The model provides a systematic framework that help decision- making to solve APP problems under fuzzy environment, and help decision maker (DM) to modify the the data until a set of satisfactory solution is obtain.
\end{abstract}

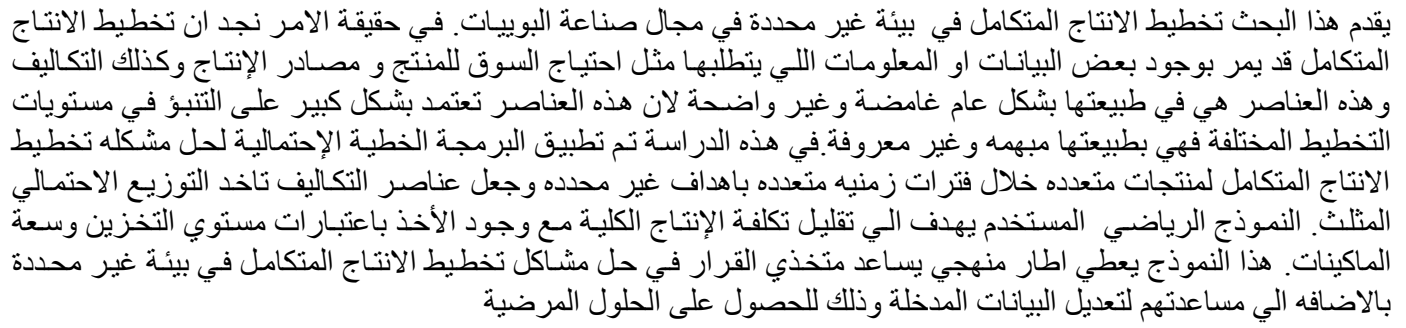

Keywords: Aggregate production planning, Fuzzy Environment, Possibilistic linear Programming

\section{INTRODUCTION}

Aggregate production planning (APP) focuses on planning process that make strategies more flexibility and understandable. It deals with matching capacity to demand of forecasted over the intermediate planning horizon varies from 3 to 18 months. It aims to set overall levels for each product family and to set decisions and policies concerning hiring, layoffs, overtime, backorders, subcontracting and inventory levels [1]. APP brought to forefront the central role of operations management by linking it with supply chain[2]. In the early 1950s, Holt, Modigliani, Muth, and Simon's ( HMMS ) work was a turning point in the direction of operations management, they made the starting point of a vast body of theoretical research in aggregate production planning. HMMS model continues to be used as a benchmark to evaluate the performance of other APP models, the core of HMMS work was a linear quadratic model of APP. This model focused on an infinite planning horizon with stationary costs, and then there's developed of this framework they tried to use computational approaches for obtaining the optimal solution, but they delt with finite planning horizon. Since then, much attention has been directed toward aggregate production planning, and different models and approaches have been developed. APP models could be classified according to the way of reaching solution into optimal models, search models, heuristic models [3] -[4], and stochastic and fuzzy optimization model[5]. The approaches to solve APP problems are centered into, linear decision rule (Holt et al., 1955), transportation (Bowman, 1956), linear programming (Hanssman and Hess, 1960), management coefficient model (Bowman, 1963), simulation model (Vergin, 1966), search decision rule (Taubert, 1968), fuzzy optimization model (Rinks, 1982), stochastic model (Sox \& Muckstadt), and pinch analysis (Singhvi et al.,2004) [1],[6]-[7].

In real- world, the input data or parameters, of APP problems such as demand, resources, costs and the objective functions are imprecise / fuzzy because some information is incomplete or unobtainable; 
researchers have developed numerous models to help to solve such APP problems, each with their own pros and cons. Traditional mathematical programming techniques clearly can not solve all fuzzy programming problems there are several studies to solve multiple objective APP problem. But generally, these studies defined the goals a fuzzy values and the fuzzy model is solved by transforming the fuzzy model into classical crisp mathematical programming problem [8]. Zimmerman [9] stated that fuzzy set theory could be used in operations research as language to model problems which contain fuzzy phenomena, as a tool to analyse such models in order to gain better insight into the problem and as an algorithm to make solution procedure more stable and faster. Since then, fuzzy mathematical programming has been used for solving APP problems[10]

Zadah proposed the fuzzy set theory after that Zimmerman introduced fuzzy set theory into linear programming (FLP). Wang \& Liang developed a fuzzy multi - objective linear programming (FMOLP) model for solving the multi-product APP [10]. Buckley [11] formulated and described a procedure for solving existing PLP problems in a standard form with no equality constraints. Lai and Hwang [12] developed an auxiliary multiple objective linear programming (MOLP) model for solving a PLP problem with imprecise objective and constraints coefficients. Then several researchers work on PLP like Hsieh and Wu, Tang, Wang and Fung, and Wang and Liang [11].

\section{SOLVING LINEAR PROGRAMMING MODELS WITH IMPRECISE COEFFICIENTS}

Linear programming model with imprecise coefficients is given in Eq. 1:

$$
\operatorname{Min} \sum_{j=1}^{n} \breve{c}_{j} x_{j}
$$

s.t. $\sum_{j=1}^{n} \breve{a}_{i j} x_{j} \leq \breve{b}_{i} \quad i=1, \ldots ., \mathrm{m}$

$$
x_{j} \geq 0 \quad j=1, \ldots \ldots, \mathrm{n}
$$

Where $\breve{a}, \quad \breve{b}$ and $\breve{c}$ are imprecise and have possibility distributions. We present Lai and Hwang approaches to solve previous model. The fuzzy objective function is defined by three corner points $(\mathrm{cp}, 0),(\mathrm{cm}, 1),(\mathrm{co}, 0)$ geometrically.

Then reformulate the equation with coefficients represented by triangular possibility distributions as:

$$
\operatorname{Min} \widetilde{z}=\sum_{i=1}^{n} c_{i}^{m} x_{i}, c_{i}^{o} x_{i}, c_{i}^{p} x_{i}
$$

In the PLP model, the objective function has imprecise coefficient with triangular possibility distribution. This imprecise objective is fully defined by three prominent points (zp, 0$),(\mathrm{zm}, 1)$, and (zo, 0$)$. The imprecise objective can be minimized by pushing the three points towards the left. Because of the vertical coordinates of the three points being fixed at either 1 or 0 , the three horizontal coordinates are the only considerations. For solving the imprecise objective requires minimizing $\mathrm{zp}, \mathrm{zm}$, and zo. To obtain the optimization of objective function there's need to solve the multiple objective linear programming MOLP by minimizes $\mathrm{zm}$, maximizes $(\mathrm{zm}-\mathrm{zp})$, and minimizes $(\mathrm{zo}-\mathrm{zm})$, rather than simultaneously minimizing zp, zm, and zo.

This lead us the following auxiliary multiobjective linear programming model

$$
\begin{aligned}
& \operatorname{Min}\left(z_{1}\right)=z^{m}=c_{i}^{m} x_{i} \\
& \operatorname{Max}\left(z_{2}\right)=\left(z^{m}-z^{p}\right)=\left(c_{i}^{m}-c_{i}^{p}\right) x_{i} \\
& \operatorname{Min}\left(z_{3}\right)=\left(z^{o}-z^{m}\right)=\left(c_{i}^{o}-c_{i}^{m}\right) x_{i}
\end{aligned}
$$

The model is transformed from single objective to multi objective linear programming problem (MOLP), a number of MOLP techniques could be applied such as utility theory, goal programming, fuzzy programming, and interactive approaches to solve the model.

In the present study, the Zimmermann's fuzzy programming [12] method with normalization process is employed. The method is described as follows:

1 - The Positive Ideal Solution ( PIS) and Negative Ideal Solution (NIS) of the three objective functions are obtained, which are

$$
\begin{array}{ll}
\mathrm{z}_{1}^{\mathrm{PIS}}=\operatorname{Min}\left(\mathrm{z}^{\mathrm{m}}\right) & \mathrm{z}_{1}^{\mathrm{NIS}}=\operatorname{Max}\left(\mathrm{z}^{\mathrm{m}}\right) \\
\mathrm{z}_{2}^{\mathrm{PIS}}=\operatorname{Max}\left(\mathrm{z}^{\mathrm{m}}-\mathrm{z}^{\mathrm{p}}\right) & \mathrm{z}_{2}^{\mathrm{NIS}}=\operatorname{Min}\left(\mathrm{z}^{\mathrm{m}}-\mathrm{z}^{\mathrm{p}}\right) \\
\mathrm{z}_{3}^{\mathrm{PIS}}=\operatorname{Min}\left(\mathrm{z}^{\mathrm{o}}-\mathrm{z}^{\mathrm{m}}\right) & \mathrm{z}_{3}^{\mathrm{NIS}}=\operatorname{Max}\left(\mathrm{z}^{\mathrm{o}}-\mathrm{z}^{\mathrm{m}}\right)
\end{array}
$$

2 - The linear membership functions of the objective functions are computed as : 


$$
\begin{aligned}
& f_{1}\left(z_{1}\right)=\left\{\begin{array}{l}
1 \\
\frac{z_{1}^{N I S}-z_{1}}{z_{1}^{N I S}-z_{1}^{\text {PIS }}} \\
O
\end{array}\right. \\
& \mathrm{z}_{1}<\mathrm{z}_{1}^{\text {PIS }} \\
& \mathrm{z}_{1}^{\mathrm{PIS}} \leq \mathrm{z}_{1} \leq \mathrm{z}_{1}^{\mathrm{NIS}} \\
& \mathrm{z}_{1}>\mathrm{z}_{1}^{\mathrm{NIS}} \\
& f_{2}\left(z_{2}\right)=\left\{\begin{array}{l}
1, \\
\frac{z_{2}-z_{2}^{\mathrm{NIS}}}{z_{2}^{\mathrm{PIS}}-\mathrm{z}_{2}^{\mathrm{NIS}}}, \\
\mathrm{O},
\end{array}\right. \\
& \mathrm{z}_{2}<\mathrm{z}_{2}^{\mathrm{PIS}} \\
& \mathrm{z}_{2}^{\mathrm{NIS}} \leq \mathrm{z}_{2} \leq \mathrm{z}_{2}^{\mathrm{PIS}} \\
& \mathrm{z}_{2}>\mathrm{z}_{2}^{\mathrm{NIS}} \\
& f_{3}\left(z_{3}\right)=\left\{\begin{array}{l}
1, \\
\frac{z_{3}^{N I S}-z_{3}}{z_{3}^{\text {NIS }}-z_{3}^{\text {PIS }}} \\
0,
\end{array}\right. \\
& \mathrm{z}_{3}<\mathrm{z}_{3}^{\mathrm{PIS}} \\
& \mathrm{z}_{3}^{\mathrm{PIS}} \leq \mathrm{z}_{3} \leq \mathrm{z}_{3}^{\mathrm{NIS}} \\
& \mathrm{z}_{3}>\mathrm{z}_{3}^{\mathrm{NIS}}
\end{aligned}
$$

Solve the following single - objective linear programming model according to Zimmermann's method

Max L

$$
\text { s.t } f_{i}\left(z_{i}\right) \geq L \quad, \mathrm{I}=1,2,3
$$

\section{PROBLEM FORMULATION}

An aggregate production planning model aims at optimizing multiple conflicting objectives; maximizing profit, minimizing costs, minimizing inventory, minimizing backorders and minimizing workforce. In fuzzy environment with uncertainties and fluctuating in demand, possibilistic linear programming model used to solve it and get the solution [12]. Because it could properly represent a typical APP problem. The demand is variable and should be satisfied in each period by normal production, inventory, over time and subcontracting.
If the demand is unsatisfied then backorder occurs, and is satisfied in the successive period.

\subsection{Model notation}

$\mathrm{N} \quad$ Number of products

$\mathrm{T} \quad$ Number pf planning horizon

$\mathrm{M}_{\mathrm{t} \max }$ Maximum machine capacity available in period $\mathrm{t}$ (machine - hour)

$\tilde{W}_{t \max } \quad$ Maximum labor level available in period $\mathrm{t}$ (machine - hour)

$\mathrm{H}_{\mathrm{t}} \quad$ Number of workers hired in period $\mathrm{t}$ (labour / period)

$\mathrm{F}_{\mathrm{t}} \quad$ Number of workers fired in period $t$ (labour / period)

$\mathrm{Q}_{\mathrm{nt}} \quad$ Units produced of product $\mathrm{n}$ during regular time of period $t$ (units)

$\mathrm{O}_{\mathrm{nt}} \quad$ Units produced of product $\mathrm{n}$ during over time of period $t$ (units)

$\mathrm{S}_{\mathrm{nt}} \quad$ Units subcontracted of product $\mathrm{n}$ in period $\mathrm{t}$ (units)

$\mathrm{I}_{\mathrm{n}} \quad$ Inventory level of product $\mathrm{n}$ in period $\mathrm{t}$ (units)

$\mathrm{B}_{\mathrm{nt}} \quad$ Backorder level of product $\mathrm{n}$ in period $\mathrm{t}$ (units)

$\tilde{a}_{n t} \quad$ Regular time production cost per unit of nth product in period $t$ (L.E / unit)

$\tilde{b}_{n t} \quad$ Over time production cost per unit of nth product in period $\mathrm{t}$ (L.E / unit)

$\tilde{c}_{n t} \quad$ Subcontracting cost per unit of nth product in period $t$ (L.E / unit)

$\tilde{d}_{n t} \quad$ Inventory carrying cost per unit of nth product in period $t$ (L.E / unit)

$\tilde{e}_{n t} \quad$ Backorder cost per unit of nth product in period t (L.E / unit)

$\tilde{k}_{n t} \quad$ Cost to hire one worker in period $\mathrm{t}$

$$
\text { (L.E / worker) }
$$

$\tilde{m}_{t} \quad$ Cost to layoff one worker in period $\mathrm{t}$

$$
\text { (L.E / worker) }
$$

\subsection{Mathematical Model}

\subsubsection{Objective function}

The objective function of this model is to minimizing the total cost covers the total production cost plus the cost of changes in labour levels 


$$
\begin{aligned}
& \operatorname{Min} \tilde{Z}=\sum_{n=1}^{N} \sum_{t=1}^{T}\left(\tilde{a}_{n t} Q_{n t}+\tilde{b}_{n t} O_{n t}+\tilde{c}_{n t} S_{n t}+\tilde{d}_{n t} I_{n t}+\tilde{e}_{n t} B_{n t}\right) \\
& +\sum_{t=1}^{T}\left(\tilde{k}_{n t} H_{t}+\tilde{m}_{t} F_{t}\right)
\end{aligned}
$$

The total production costs include five components, $\sum_{n=1}^{N} \sum_{t=1}^{T} \tilde{a}_{n t} Q_{n t}$ are the regular time production costs, $\sum_{n=1}^{N} \sum_{t=1}^{T} \tilde{b}_{n t} O_{n t}$ are the over time production costs, $\sum_{n=1}^{N} \sum_{t=1}^{T} \tilde{c}_{n t} S_{n t}$ are the subcontracting costs, $\sum_{n=1}^{N} \sum_{t=1}^{T} \tilde{d}_{n t} I_{n t}$ are the inventory carrying costs, $\sum_{n=1}^{N} \sum_{t=1}^{T} \tilde{e}_{n t} B_{n t}$ are the backorder costs, and $\sum_{t=1}^{T}\left(\tilde{k}_{n t} H_{t}+\tilde{m}_{t} F_{t}\right)$ specifies the costs of changes in labour levels, including the costs to hire and layoff workers.

\subsubsection{Constraints}

\section{Carrying Inventory Constraint}

The inventory quantity constraint is general form the sum of regular and over time production, existing inventory level, and subcontracting and backorder quantities. This inventory level should cover the market demand. It must be noted that the model assumes fulfilling any backorder directly from the subsequent period.

$$
\begin{aligned}
\mathrm{I}_{\mathrm{nt}-1}-\mathrm{B}_{\mathrm{nt}-1}+\mathrm{Q}_{\mathrm{nt}}+\mathrm{O}_{\mathrm{nt}}+ & \mathrm{S}_{\mathrm{nt}}-\mathrm{I}_{\mathrm{nt}}+\mathrm{B}_{\mathrm{nt}}=\tilde{\mathrm{D}}_{\mathrm{nt}} \\
& \forall \mathrm{n}, \forall \mathrm{t}
\end{aligned}
$$

The demand $\tilde{\mathrm{D}}_{\mathrm{nt}}$ denotes the imprecise forecast demand of the nth product in period $t$.

\section{Labor Levels Constraints}

Equation $(3,4)$ represents the labor level constraints, Equation (3) assumes that the equality of new hired and layoffs in period t. Equation (4) presents the actual labor levels which can calculated by multiple the working hours of labor per unit of nth product in period $t$ (regular and overtime). This actual level cannot exceed the maximum available labor levels in each period.

$$
\sum_{t=1}^{T} I_{t}-H_{t}=\mathrm{O} \forall \mathrm{t}
$$

$$
\sum_{n=1}^{N} i_{n t}\left(Q_{n t}+O_{n t}\right) \leq \tilde{W}_{t \max } \forall \mathrm{t}
$$

It must be noted that the maximum available labor levels ( $\tilde{\mathrm{W}}_{\mathrm{t} \max }$ ) is imprecise owing to uncertain labor available in the market.

\section{Machine Capacity Constraints}

Actual machine capacity that can be calculated by multiple of machine usage hours per unit of nth product in period $t$ during regular and overtime. The upper limitation is the maximum available machine capacity in period t. Both usage hours $\left(\widetilde{r}_{n t}\right)$ and available capacity in period $t\left(\tilde{\mathbf{M}}_{t_{\max }}\right)$ are considered imprecise in nature.

$$
\sum_{n=1}^{N} \tilde{r}_{n t}\left(Q_{n t}+O_{n t}\right) \leq \tilde{M}_{t \max } \forall \mathrm{t}
$$

Non - negativity constraints on decision variables are presented as follows

$$
\mathrm{Q}_{\mathrm{nt}}, \mathrm{O}_{\mathrm{nt}}, \mathrm{S}_{\mathrm{nt}}, \mathrm{I}_{\mathrm{nt}}, \mathrm{B}_{\mathrm{nt}}, \mathrm{H}_{\mathrm{t}}, \mathrm{F}_{\mathrm{t}} \geq \mathrm{O}
$$

$$
\forall \mathbf{n}, \forall \mathbf{t}
$$

\subsection{PLP model}

The Possibilistic Linear Programming (PLP) method can solve general imprecise APP problems through interactive process with the DM and provides the overall DM's satisfaction under the strategy of minimizing the most possible values and the risk of obtaining higher objective values and maximizing the possibility of obtaining lower objective values. PLP as a special case of fuzzy linear programming (FLP) deals with fuzzy data which is usually formulated by subjective preference - based membership function, while PLP deals with imprecise data modeled by possibilistic distribution on subjective or objective bases. PLP approach is not only provides more computational efficiency and more flexible doctrines, but also supports possibilistic decision - making in an uncertain environment [12].

In the present model, the fuzzy inequalities are converted to the crisp value by applying the triangular distribution. Equations from 1 to 9 describe the convert of the model to crisp values. 


$$
\begin{aligned}
& \operatorname{Min}\left(z_{1}\right)=z^{m} \\
& =\sum_{n=1}^{N} \sum_{t=1}^{T}\left[a_{n t}^{m} Q_{n t}+b_{n t}^{m} O_{n t}+c_{n t}^{m} S_{n t}+d_{n t}^{m} I_{n t}+e_{n t}^{m} B_{n t}\right]+ \\
& \sum_{t=1}^{T}\left(k_{n t}^{m} H_{t}+m_{t}^{m} F_{t}\right) \\
& \operatorname{Max}\left(z_{2}\right)=\left(z^{m}-z^{p}\right) \\
& =\sum_{n=1}^{N} \sum_{t=1}^{T}\left[\left(a_{n t}^{m}-a_{n t}^{P}\right) Q_{n t}+\left(b_{n t}^{m}-b_{n t}^{P}\right) O_{n t}+\left(c_{n t}^{m}-c_{n t}^{P}\right) S_{n t}\right. \\
& \left.+\left(d_{n t}^{m}-d_{n t}^{P}\right) I_{n t}+\left(e_{n t}^{m}-e_{n t}^{P}\right) B_{n t}\right]+ \\
& \sum_{t=1}^{T}\left[\left(k_{n t}^{m}-k_{n t}^{P}\right) H_{t}+\left(m_{t}^{m}-m_{t}^{P}\right) F_{t}\right] \\
& \operatorname{Min}\left(z_{3}\right)=\left(z^{o}-z^{m}\right) \\
& =\sum_{n=1}^{N} \sum_{t=1}^{T}\left[\left(a_{n t}^{o}-a_{n t}^{m}\right) Q_{n t}+\left(b_{n t}^{o}-b_{n t}^{m}\right) O_{n t}+\left(c_{n t}^{o}-c_{n t}^{m}\right) S_{n t}\right. \\
& \left.+\left(d_{n t}^{o}-d_{n t}^{m}\right) I_{n t}+\left(e_{n t}^{o}-e_{n t}^{m}\right) B_{n t}\right]+ \\
& \sum_{t=1}^{T}\left[\left(k_{n t}^{o}-k_{n t}^{m}\right) H_{t}+\left(m_{t}^{o}-m_{t}^{m}\right) F_{t}\right] \\
& I_{n t-1}-B_{n t-1}+Q_{n t}+O_{n t}+S_{n t}-I_{n t}+B_{n t}= \\
& w_{1} D_{n t}^{P}+w_{2} D_{n t}^{m}+w_{3} D_{n t}^{o} \\
& \sum_{\mathrm{n}=1}^{\mathrm{N}} \mathrm{i}_{\mathrm{nt}}\left(\mathrm{Q}_{\mathrm{nt}}+\mathrm{O}_{\mathrm{nt}}\right) \leq \mathrm{w}_{1} \mathrm{~W}_{\mathrm{t} \text { max }}^{\mathrm{P}}+\mathrm{w}_{2} \mathrm{~W}_{\mathrm{t} \text { max }}^{\mathrm{m}}+\mathrm{w}_{3} \mathrm{~W}_{\mathrm{t} \text { max }}^{\mathrm{o}} \\
& \sum_{t=1}^{T} H_{t}-F_{t}=\mathrm{O} \\
& \sum_{n=1}^{N} r_{n t}^{P}\left(Q_{n t}+O_{n t}\right) \leq M_{t \max }^{P} \forall \mathbf{t} \\
& \sum_{\mathrm{n}=1}^{\mathrm{N}} \mathrm{r}_{\mathrm{nt}}^{\mathrm{m}}\left(\mathrm{Q}_{\mathrm{nt}}+\mathrm{O}_{\mathrm{nt}}\right) \leq \mathrm{M}_{\mathrm{t} \max }^{\mathrm{m}} \forall \mathrm{t} \\
& \sum_{\mathrm{n}=1}^{\mathrm{N}} \mathrm{r}_{\mathrm{nt}}^{\mathrm{o}}\left(\mathrm{Q}_{\mathrm{nt}}+\mathrm{O}_{\mathrm{nt}}\right) \leq \mathrm{M}_{\mathrm{t} \max }^{\mathrm{o}} \forall \mathrm{t}
\end{aligned}
$$

After getting the solution make convert from MOLP to equivalent $\mathrm{LP}$ to satisfied factor $\mathrm{L}$ Max L

$$
\mathrm{L} \leq \mathrm{f}_{\mathrm{i}}\left(\mathrm{z}_{\mathrm{i}}\right), \quad \mathrm{i}=1,2,3,
$$

The algorithm PLP for solving the APP decision problem is as follows:

Step Formulate the PLP model for multi (1): $\quad$ product APP decision problem.

Step Model the imprecise coefficients (2): $\quad\left(\tilde{\mathrm{a}}_{\mathrm{nt}}, \tilde{\mathrm{b}}_{\mathrm{nt}}, \tilde{\mathrm{c}}_{\mathrm{nt}}, \tilde{\mathrm{d}}_{\mathrm{nt}}, \tilde{\mathrm{e}}_{\mathrm{nt}}, \tilde{\mathrm{k}}_{\mathrm{nt}}, \tilde{\mathrm{n}}_{\mathrm{nt}}, \tilde{\mathrm{m}}_{\mathrm{nt}}\right)$ and right hand side $\left(\tilde{\mathrm{D}}_{\mathrm{nt}}, \tilde{\mathrm{W}}_{\mathrm{nt}}, \tilde{\mathrm{M}}_{\mathrm{nt}}\right)$ using triangular possibility distribution.

Step Develop three new crisp objective (3): functions of the auxiliary MOLP problem that are equivalent simultaneously minimizing the most possible total cost value, maximizing the possibility of obtaining lower costs, and minimizing the risk of obtaining higher costs.

Step Using the weighted average method or the (4): $\quad$ fuzzy ranking concept.

Step Specify the linear membership functions (5): for three new objective functions, and then convert the auxiliary MOLP problem into an equivalent LP model using the fuzzy decision.

Step Solve and modify the model interactively. (6): If the DM is not satisfied with the initial solution then the model must be modified until a satisfactory solution is found.

\section{APPLICATION IN PAINT FACTORY}

The company under study is a paint factory that endeavors to be the largest producer of paints through the Arab and African countries. It also exerts all possible efforts to be strongly available in the global paints consumer markets and to maintain the technical, economical, and environmental efficiency of production process. The factory produces three types of paints:

1 - Car paints: it presents $52 \%$ of the total production,

2 - Wood paints: it presents $22 \%$ of the total production, and

3 -Construction paints: it presents $26 \%$ of the total production.

The company divided their products into 34 groups according to the similarity in manufacturing process the fifth group is selected to be studied called varnish products as a company strategy they are treating group five as a separate group from cost and manufacturing procedure. The company planning horizon is four months. Due to similarity of physical nature in this group of products they have been subdivided into two families based on additives to the paints, brilliant and matt varnish. The company has six days a week and twenty - four hours a day. The day divided into two 12 hour shifts, the number of working days is 25 day/month. The hiring cost per 
employee is 750 (L.E) and for firing is 550 (L.E). The production cost calculated for the $\mathrm{Kg}$ as average cost of material, machine usage and, labor is equal to 13 (L.E./Kg) and selling price is 15 (L.E./Kg).

Table (1) represents the max labor time and max machining times for each period with triangular possibility distributions from period to period.

Solve the model interactively the total cost is imprecise and has a triangular distribution of $(0,7800,8320)$ and overall degree of DM satisfaction with multiple goal values is 0.943

\section{CONCLUSION}

1-The possibilistic linear programming approach is used in the present research to solve most real- world APP problems involving imprecise parameters. The model constitutes a systematic framework that facilities the decision making process enabling the DM interactively to modify the imprecise data and related model parameters until a satisfactory solution is found in primary analysis of the PLP approach, its linear and single objective function with imprecise objective value and constraints. Also it covers product family with multi - period planning horizon with limitation in machine capacity and imprecise all costs like: regular time production cost, overtime production cost, inventory carrying cost, hiring, layoff and labor level. Consider subcontracting and backordering. Finally, the PLP model is the most practical for solving APP decision problems and can generate better decision than other model.

2- When comparing LP approach with PLP approach, the optimal value when applying LP to minimize the total cost is ( $\vee \wedge .$.$) and in construct$ with the PLP approach improved results were $\left(Z_{1}-Z_{2}\right.$, $\left.Z_{1}, Z_{1}+Z_{3}\right)(0,7800,8320)$ the improved APP plan is obtain by PLP approach under an acceptable degree of DM satisfaction in fuzzy environments.

Table 1, Max labor and machine time for each period with triangular possibility distribution

\begin{tabular}{|c|c|c|c|c|c|}
\hline \multirow{2}{*}{ Parameters } & Period & Units & & & \\
\hline & Jan. & Feb. & March & April & \\
\hline $\begin{array}{l}\text { Available Labor } \\
\text { Working hrs/month }\end{array}$ & $\begin{array}{c}(3560,3600, \\
3640)\end{array}$ & $\begin{array}{c}(3400,3456, \\
3300)\end{array}$ & $\begin{array}{c}(3560,3600, \\
3640)\end{array}$ & $\begin{array}{c}(2650,2736, \\
2800)\end{array}$ & Man - hr \\
\hline $\begin{array}{l}\text { Available Filling \& } \\
\text { Mixing machine } \\
\text { hrs/month }\end{array}$ & $(360,400 * *, 430)$ & $(450,500,540)$ & $\begin{array}{c}(540,600, \\
650)\end{array}$ & $\begin{array}{c}(450,500, \\
540)\end{array}$ & Machine - hr \\
\hline
\end{tabular}

Table 2, Forecast demand data

\begin{tabular}{|c|c|c|c|c|}
\hline \multirow{2}{*}{ Item } & \multicolumn{3}{|c|}{ Period } \\
\cline { 2 - 5 } & Jan. & Feb. & March & April \\
\hline D1 & $(900,1000,1080)$ & $(2750,3000,3200)$ & $(4600,5000,5300)$ & $(1080,2000,2100)$ \\
\hline D2 & $(900,1000,1080)$ & $(450,500,540)$ & $(2750,3000,3200)$ & $(2300,2500,2650)$ \\
\hline
\end{tabular}

Table 3, Related operating cost data

\begin{tabular}{|c|c|c|}
\hline Item & Regular time cost & Inventory carrying cost \\
\hline D1 & $(17,20,22)$ & $(0.27,0.3,0.32)$ \\
\hline D2 & $(8,10,11)$ & $(0.13,0.15,0.16)$ \\
\hline
\end{tabular}


3 - The LP solutions often were used as a starting point of the PIS and NIS, and both intervals must cover the LP solutions. For example, three crisp objective functions of the auxiliary MOLP problem presented in the paint case were respectively solved using the crisp single-goal LP model, and the corresponding PIS and NIS of the initial solution are specified as summarized in Table(4).

Table 4, summarized solution values

\begin{tabular}{|c|c|c|c|c|}
\hline Item & $\begin{array}{c}\mathrm{LP} \\
\mathrm{Z}_{1}\end{array}$ & $\mathrm{LP} \mathrm{Z}_{2}$ & $\begin{array}{c}\mathrm{LP} \\
\mathrm{Z}_{3}\end{array}$ & ( PIS,NIS) \\
\hline Objective & Min & Max $\mathrm{Z}_{2}$ & $\begin{array}{c}\text { Min } \\
\mathrm{Z}_{3}\end{array}$ & \\
\hline $\mathrm{Z}_{1}$ & 7800 & - & - & $\begin{array}{c}(7773.500, \\
500000)\end{array}$ \\
\hline $\mathrm{Z}_{2}$ & - & 500000 & - & $\begin{array}{c}(500000, \\
847.1333)\end{array}$ \\
\hline $\mathrm{Z}_{3}$ & - & - & 520 & $\begin{array}{c}518.2333, \\
500000)\end{array}$ \\
\hline
\end{tabular}

4- The PLP provides the overall degree of DM satisfaction under the proposed strategy of minimizing the most possible value and the risk of obtaining higher total costs, and maximizing the possibility of obtaining lower total costs. If the solution is $\mathrm{L}=1$; then each goal is fully satisfied; if $0<\mathrm{L}<1$; then all of the goals are satisfied at the level of $\mathrm{L}$, and if $\mathrm{L}=0$; then none of the goals are satisfied. For the present case PLP solution

$(0,7800,8320)$ the $\mathrm{L}$ value is equal to 0.943

\section{REFERENCES}

[1] Wang, R. and Liang, T. "Application of Fuzzy Multi-Objective Linear Programming to Aggregate Production Planning" Computer \& Industrial Engineering. 46 ( 2004) : 17-41

[2] Fung, R., Tang, J., and Wang, D. "Multiproduct Aggregate Production Planning with Fuzzy Demand and fuzzy Capacities." IEEE Transactions on Systems, Man, and Cybernetics - Part A: Systems and Humans, 33.3,(2003): 302- 313
[3] Pradenas, L.,Penailillo, F. and Ferland, J. "Aggregate Production Planning A new Algorithm." Electronic Notes of Discrete Mathematics. 18 (2004): 193-199

[4] Ghazy,M.,'Multi Objectives Aggregate Production Plan By The Aid of A Genetic Alogrithm" Msc., the arab academy for science and technology, Alexandria.(2005)

[5] Behrokh, K.” Aggregate Production Planning Models Incorporating Dynamic Productivity" Ph.D. The university of Oklahoma ( 1979)

[6] Singhal ,J. and Singhal, K. "Holt, Modigliani, Muth, and Simon's Work and Its Role in The Renaissance and Evolution of Operations Management" Journal of Operations Management. 25 (2007): 300-309

[7] R.A. Aliev, , , B. Fazlollahi , B.G. Guirimov, and R.R. Alievc, "Fuzzy-genetic approach to aggregate production-distribution planning in supply chain management" Information SciencesVolume 177, Issue 20, 15 October 2007, 4241-4255

[8] Adil Baykasoglu, Tolunay Gocken" Multiobjective aggregate production planning with fuzzy parameters" Advanced in Engineering Software, 41(2010), 1124-1131.

[9] Jain, A. and Palekar, U." Aggregate Production Planning for Continuous Reconfigurable Manufacturing Process." Computer \& Operation Research. 32 (2005): 1213-1236

[10] Alfred L. Guiffrida, Rakesh Nagi” Fuzzy Set Theory Applications in Production Management Research:A Literature Survey" Journal of Intelligent Manufacturing, Volume 9,(1998):39-56

[11] Ömer Faruk Baykoç, and Ümit Sami Sakalli "An Aggregate Production Planning Model for Brass Casting Industry in Fuzzy Environment" World Academy of Science, Engineering and Technology (52) 2009

[12] Wang, R. and Liang, T.” Applying possibilistic linear programming to aggregate production planning" International Journal of Production Economics 98 (2005): 328-341 